\title{
Competitive Ionization of Tetraphenylporphyrin in a Laser-Generated Metal Ion Plasma
}

\author{
Junggi Ha, Jeremiah D. Hogan, and David A. Laude, Jr. \\ Department of Chemistry and Biochemistry, The University of Texas at Austin, Austin, Texas, USA
}

\begin{abstract}
The ionization of tetraphenylporphyrin (TPP) in a laser-desorbed metal ion plasma is examined by Fourier transform ion cyclotron resonance (FT-ICR) mass spectrometry. Competitive reaction pathways observed to generate abundant molecular ion species include electron detachment, cation attachment, charge exchange, metallation, and transmetallation in the positive ion mode and electron capture, metallation, and transmetallation in the negative ion mode. In general, cation attachment reactions dominate positive ion spectra below the laser irradiance threshold for plasma ignition, although the metallation product from $[\mathrm{TPP}]^{+\cdot}$ reaction with the metal atom, $M$, is observed. Negative ion products are not observed in the FT-ICR spectrum when a plasma is not formed. Under plasma ignition conditions, positive ion spectra include [TPP] ${ }^{+\cdot}$ formed by charge exchange with $\mathrm{M}^{+}$, which is also present in the spectrum. Negative ion spectra are dominated by [TPP] ${ }^{-*}$, which is formed by attachment to thermal electrons generated in the plasma. Metallation reactions involving TPP and the metal substrate are examined. Positive ion metallation products are observed both in the absence of a plasma through reaction of [TPP] ${ }^{+}$with $\mathrm{M}$ and by a second pathway under plasma ignition conditions through reaction of TPP with $\mathbf{M}^{+}$. In negative ion mode, metallation is only observed under plasma ignition conditions through reaction of [TPP] $]^{-}$with $\mathrm{M}$. Observation of metallated products is found to be consistent with formation of stable metal oxidation states in the metallated porphyrin. (J Am Soc Mass Spectrom 1993, 4, 159-167)
\end{abstract}

$\mathrm{T}$ he fundamental importance of metalloporphyrin chemistry to the fields of biology and geology has prompted the development of analytical techniques to characterize structure, physical properties, and chemical reactivity. Thus, with the demonstration that direct insertion probe electron ionization mass spectrometers would generate spectra featuring molecular ions of both free and metallated porphyrins, a rich history involving mass spectrometry of porphyrins has developed [1-6]. Numerous soft ionization techniques have been successful in generating abundant positive and negative molecular ion species for a wide array of porphyrins. More recently, fragmentation of the pyrollic macrocycle for sequencing purposes has been accomplished with $\mathrm{H}_{2}$ and $\mathrm{NH}_{3}$ chemical ionization [7-11].

Porphyrin mass spectrometry is intriguing because of the facility with which molecular species are generated by competing ionization pathways. For example, the large, delocalized aromatic ring structure accommodates large amounts of internal energy to allow the

Address reprint requests to David A. Laude, Jr., Department of Chemistry and Biochemistry. The University of Texas at Austin, Austin, TX 78712 . molecular ion to dominate $70-\mathrm{eV}$ electron ionization spectra. Mass spectra from field desorption [12], plasma desorption [13], fast atom bombardment [14-19], and laser desorption ionization (LDI) [20-23] sources also generate proton and cation attachment products. In addition, the ionization potential (IP) of porphyrins is sufficiently low (e.g., the IP for porphine is $6.6 \mathrm{eV}$ [24]) that electron detachment or gas-phase charge exchange with surrounding organic and metal ions will occur under appropriate conditions. The relatively high electron affinity of porphyrins, $1.5-1.8 \mathrm{eV}$ [25], is sufficient for electron capture products to dominate negative ion spectra [26-29].

In the work presented here, this ensemble of competitive gas-phase porphyrin reactions is examined by LDI/Fourier transform ion cyclotron resonance (FTICR) mass spectrometry. Laser desorption ionization was selected because all of the reagents required for the reactions noted previously can be formed above the sample surface under plasma ignition conditions. 'I he formation of a plasma is a general consequence of laser ablation of metal substrates above a threshold power density that typically exceeds approximately $10^{8} \mathrm{~W} / \mathrm{cm}^{2}$ [30-32]. Laser plasma ignition is often exploited to generate metal ions to be used as reactive

Received April 30, 1992

Revised July 31, 1992 $1044-0305 / 93 / \$ 6.00$ 
species in gas-phase ion-molecule reaction studies [33-35]. The FT-ICR technique has been demonstrated by several groups to be an excellent detector of LDI products, specifically LDI of porphyrins $[20-23,34]$. For example, Brown and Wilkins [21] showed that LDI/FT-ICR of free porphyrins and metalloporphyrins at high laser fluence yielded primarily the porphyrin cation and anion with modest side-chain fragmentation. At lower laser irradiance in the presence of an alkalai metal salt, cation attachment processes were favored. More recently, Nguyen et al. [22] used LDI/FT-ICR to examine dimethyl 8-acetyl-33,7,12,17tetramethylporphyrin-2,18-dipropianoate. They found that the porphyrin cation and anion dominated at low laser irradiance, with extensive fragmentation at higher laser irradiance. No metallation products were observed at laser irradiances to $3.8 \times 10^{7} \mathrm{~W} / \mathrm{cm}^{2}$. Irikura and Beauchamp [34] demonstrated that selective metallated porphyrins form from laser-desorbed metal cations that subsequently reacted with gas-phase porphine in the trapped ion cell; estimated metalporphyrin bond energies for these cations were greater than $127 \mathrm{kcal} / \mathrm{mol}$; however, generation of metallated anions directly from the metal was not observed, with the explanation given that metal anions, $\mathrm{M}^{-}$, were not formed in good yield by LDI.

Even with the LDI/FT-ICR experiments performed to date, an understanding of the factors that contribute to competitive cation attachment, charge exchange, electron capture or detachment, metallation, and transmetallation reactions is incomplete. From an analytical perspective, appropriate control of the experiment, including sample preparation and laser conditions, is critical to provide the necessary reagents to generate the porphyrin product of interest for structure determination or subsequent reaction. Of more general interest is whether reactions occurring in the high-energy laser-generated plasma are in any way consistent with the results observed for porphyrin chemistry that occurs in solution. As will be discussed, it is found that product stabilities for metallation reactions that occur in a laser-desorbed plasma correlate well with metalloporphyrin products that exhibit stable metal oxidation states in solution. This finding is important because it suggests that plasma ignition LDI might be used for generating important bioporphyrin species for subsequent gas-phase reactions in the trapped ion cell with detection by FT-ICR. In particular, this technique may be a convenient method for synthesizing any desired metallated porophyrin directly from the porphyrin precursor without any other pretreatment or synthesis.

\section{Experimental}

\section{Instrumentation}

Experiments were conducted with an FT-ICR instrument, featuring a 3.0-T superconducting magnetic, a 5 -cm cubic trapped ion cell, a vacuum chamber diffu- sion pumped to below $10^{-8}$-torr pressure, and a probe-mounted fiber-optic-based laser desorption interface [36]. Data acquisition and processing were controlled with an Extrel FTMS-2000 data system and software. A pulsed Nd:YAG model DCR-11 from Spectra Physics (Mountain View, CA) was used to desorb and generate the plasma.

\section{Sample Preparation}

Samples of tetraphenylporphyrin (TPP), obtained from Aldrich Chemical Co. (Milwaukee, WI) and used without additional purification, were dissolved in chloroform and spray deposited onto spinning cylindrical probe tips fashioned from stainless steel. In early experiments, stainless steel probe tips were sandblasted between sample depositions to eliminate cross contamination. This had the effect, however, of providing a source of $\mathrm{Al}_{2} \mathrm{O}_{3}$ on the probe surface that under certain conditions participated in the LDI process. For some experiments it was desirable to provide a source of potassium ions to enhance cation attachment processes, and $\mathrm{KBr}$ was dissolved in methanol and aerosol sprayed onto the probe tip prior to deposition of TPP.

A fiber-optic-mounted sample probe used for all LDI/FT-ICR experiments is described elsewhere [36]. Briefly, TPP-sprayed probe tips were mounted on a 0.25 -in. o.d. probe that was positioned in a 0.75 -in. o.d. probe assembly that also housed the fiber-optic. This 0.25 -in. probe could be rotated and translated to provide several hundred laser firings on fresh sample. The probe was inserted into the analyzer chamber along the $z$-axis centerline of the trapped ion cell to within 2 $\mathrm{cm}$ of an $80 \%$ transmissive mesh trap plate. Pressure in the analyzer chamber was allowed to return below $2 \times 10^{-8}$ torr prior to executing the LDI/FT-ICR experiment.

\section{Data Acquisition and Processing}

The FT-ICR pulse sequence commenced with a single laser firing of a 9-ns Q-switched, 1064-nm pulse that delivered up to $23 \mathrm{~mJ}$ of laser energy (measured with a Gentec model 200 joulemeter) through the fiber-optic to the sample. With the fiber positioned within $1 \mathrm{~mm}$ of the probe tip, unfocused light exiting the fiber creates a spot measuring $0.9 \mathrm{~mm}^{2}$ on the probe surface that corresponds to a laser irradiance from below $10^{7}$ to $3 \times 10^{8} \mathrm{~W} / \mathrm{cm}^{2}$.

As a more direct measure of the extent of plasma formation associated with each firing of the laser, a LeCroy (Chestnut Ridge, NY) model 9400 digital storage oscilloscope recorded the negative excursion of the effective trap potential as the laser-desorbed plasma passed through the trapped ion cell. This trapping potential depression, which accompanies several of the LDI/FT-ICR spectra to be shown, provides a qualitative measure of the charged-particle density. Support for this assumption comes from earlier work that indi- 
cated that the potential depression created at biased trap plates by selected electron or metal ion populations increased with increasing laser irradiance [32].

Following the laser event, a several hundred millisecond delay period allowed system base pressures to return to the low $10^{-8}$-torr region. For many experiments, as will be specified later, double-resonance events at the cyclotron resonance frequencies of strong matrix ions and suspected precursor ions would be applied to eject ions from the cell. Either the Extrel frequency synthesizer was used to facilitate sequential ejection of unwanted ions during the delay or a secondary synthesizer output, consisting of superimposed waveforms at multiple frequencies, was created with a LeCroy model 9100 arbitrary function generator and applied to the excite plates [37].

Broadband cyclotron excitation prior to detection was accomplished with a linear frequency sweep at $1000 \mathrm{~Hz} / \mu \mathrm{s}$ over a $2.66-\mathrm{MHz}$ range. Nominal mass resolution to about $1500 \mathrm{Da}$ was achieved in broadband mode with $128 \mathrm{~K}$ data points acquired for an $800-\mathrm{kHz}$ bandwidth. Transients were processed with sine bell apodization, augmentation with an equivalent number of data points, and magnitude-mode Fourier transformation.

Negative ion FT-ICR spectra were acquired by maintaining trapping potentials at $-0.75 \mathrm{~V}$ continuously, except during the quench event. Positive ion spectra were acquired with a trap potential continuously applied at $0.75 \mathrm{~V}$. Spectra are the result of a single laser firing on fresh sample or, for depth-profiling studies, successive laser firings in the same probe position.

\section{Results and Discussion}

In this report the following nomenclature is used:

TPP, free-base TPP
$\left[\mathrm{TPP}^{+}{ }^{+}\right.$, TPP radical cation
[TPP $^{-}$, TPP radical anion
$[\mathrm{TPP}+\mathrm{M}]^{+}$, cationized TPP
$[\mathrm{TPP}+\mathrm{M}]^{-}$, anionized TPP
$[\mathrm{TPP}-2 \mathrm{H}+\mathrm{M}]^{+}$, metallated TPP anion
$[\mathrm{TPP}-2 \mathrm{H}+\mathrm{M}]^{-}$, metallated TPP cation.

As will be discussed, metal valency determines whether the metallated TPP ion is a radical.

\section{General Features of Tetraphenylporphyrin Spectra}

Presented in Figure 1 are representative positive and negative ion FT-ICR spectra generated by LDI at $3 \times$ $10^{8} \mathrm{~W} / \mathrm{cm}^{2}$ on a sample consisting of TPP deposited with $\mathrm{KBr}$ on a sandblasted stainless steel probe. A wealth of molecular ion species generated by competitive gas-phase reactions in the plasma are shown. As expected, the positive ion spectrum exhibits [TPP] ${ }^{+\cdot}$ as the base peak at $m / z 614$. In contrast with the observations of Nguyen et al. [22], metallation reaction
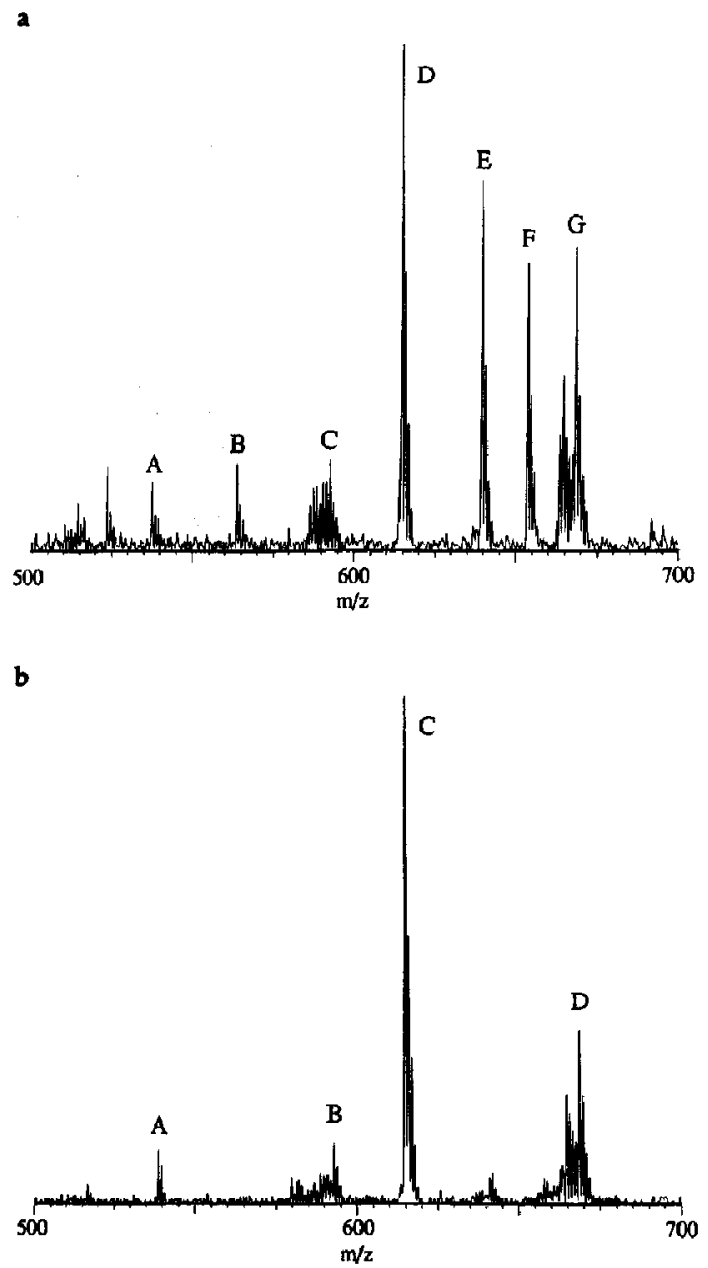

Figure 1. LDI/FT-ICR spectra of TPP deposited with $\mathrm{KBr}$ on a sandblasted stainless steel probe tip. A laser power density of approximately $3 \times 10^{8} \mathrm{~W} / \mathrm{cm}^{2}$ was used; $\mathrm{K}^{+}$and $\mathrm{Br}^{-}$were ejected from the cell following desorption for positive and negative ion spectra, respectively. (a) Pusitive ion noude with $\mathrm{A}=$ $[\mathrm{TPP}-77]^{+} ; \mathrm{B}=[(\mathrm{TPP}-2 \mathrm{H}+\mathrm{Al})-77]^{+} ; \mathrm{C}=[(\mathrm{TPP}-\mathbf{2 H}+$ $\mathrm{Fe})-77]^{+} ; \quad \mathrm{D}=\mathrm{TPP}^{+} ; \quad \mathrm{E}=[\mathrm{TPP}-2 \mathrm{H}+\mathrm{Al}]^{+} ; \mathrm{F}=[\mathrm{TPP}+$ $\mathrm{K}^{+} ; \mathrm{G}=[\mathrm{TPP}-2 \mathrm{H}+\mathrm{Fe}]^{+}$. (b) Negative ion mode with $\mathrm{A}=$ $[\mathrm{TPP}-77]^{-} ; \mathrm{B}=[(\mathrm{TPP}-2 \mathrm{H}+\mathrm{Fe})-77]^{-} ; \mathrm{C}=\mathrm{TPP}^{-} ; \mathrm{D}=$ $[\mathrm{TPP}-2 \mathrm{H}+\mathrm{Fe}]^{-}$.

products yielding ions at $m / z 639,664,667$, and 668 corresponding to $[\mathrm{TPP}-2 \mathrm{H}+\mathrm{M}]^{+}$, where $\mathrm{M}={ }^{27} \mathrm{Al}$, ${ }^{52} \mathrm{Cr},{ }^{55} \mathrm{Mn}$, and ${ }^{56} \mathrm{Fe}$, respectively, were observed and in fact dominate the spectra for many metal substrates. These metallation reactions occur with concomitant loss of hydrogen. The ${ }^{52} \mathrm{Cr},{ }^{55} \mathrm{Mn}$, and ${ }^{56} \mathrm{Fe}$ were generated from the stainless steel substrate, and ${ }^{27} \mathrm{Al}$ was present from prior sandblasting of the probe tip. A cation attachment reaction also yielded an ion at $m / z$ 653 that corresponded to [TPP $+\mathrm{K}]^{+}$. The fragmentation pattern in the $m / z$ 537-591 region corresponded to loss of a phenyl group from [TPP] ${ }^{+\cdot}$ and from the metallation products, but fragmentation associated 
with the cation attachment product $[\mathrm{TPP}+\mathrm{K}]^{+}$was not observed.

The negative ion spectrum of TPP was similar to the positive ion spectrum and included [TPP] ${ }^{-}$as the base peak and fragment ions corresponding to loss of phenyl groups from all molecular species. In contrast with Irikura and Beauchamp [34], negative ion metallation reaction products were observed in excellent yield. Notable distinctions from the positive ion spectrum included the absence of cation attachment products and a negligible metallation product ion from the $[\mathrm{TPP}]^{-}$reaction with $\mathrm{Al}$.

Of the ions produced in Figure 1, the process leading to formation of [TPP $+\mathrm{K}^{+}$at $\mathrm{m} / \mathrm{z} 653$ is most studied and best understood because it is also the vehicle by which most infrared LDI/time-of-flight and LDI/FT-ICR mass spectra of organic molecules are produced [38-44]. Specifically, a weak ionic association results from the gas-phase ion-molecule reaction $[20-23,35]$ between an intact neutral TPP and a precursor ion from the salt. The $[\mathrm{TPP}+\mathrm{K}]^{+}$formation in Figure 1 was shown by double-resonance ejection experiments to involve $\mathrm{K}_{2} \mathrm{Br}^{+}$as the primary reactive ion, as shown in reaction 1 [45-47]:

$$
\mathrm{TPP}+\mathrm{K}_{2} \mathrm{Br}^{+} \rightarrow[\mathrm{TPP}+\mathrm{K}]^{+}+\mathrm{KBr}
$$

The macrocyclic center is the likely site for potassium transfer and attachment because the pyrrole functionality is more prone than the benzene ring to attachment reaction with metal cations [48]. Potassium attachment to octacthylporphyrin is additional evidence that the porphyrin ring is the reaction site. The observation that cleavage of a phenyl ring does not accompany potassium attachment suggests that low-energy processes involved do not seriously perturb the molecular orbital system of neutral porphyrin.

In contrast with cation attachment, the chemistry associated with formation of [TPP] ${ }^{+\cdot}$ in the LDI plasma is not as well documented. Given the low IP of TPP, $[\mathrm{TPP}]^{+\cdot}$ is likely to form either due to charge exchange with metal ions in the plasma (reaction 2) or electron detachment as a consequence of thermal effects at the surface or in the plasma (reaction 3):

$$
\begin{aligned}
\mathrm{TPP}+\mathrm{M}^{+} & \rightarrow[\mathrm{TPP}]^{+\cdot}+\mathrm{M} \\
\mathrm{TPP} & \rightarrow[\mathrm{TPP}]^{+\cdot}+\mathrm{e}^{-}
\end{aligned}
$$

Distinction between the two processes should be possible but in practice is difficult to accomplish. For example, although a wide range of metal IPs surround the IP of TPP, the lascr plasma ignition process generates ions with kinetic energies extending to the hundreds of electron volts $\left[32,36_{r} 48-50\right]$. As a consequence, kinetically driven endothermic processes may interfere [51, 52]. Charge exchange might be distinguished by performing double-resonance experiments, as was done with cation attachment reactions; ejection of suspected
$\mathrm{M}^{+}$precursors with consequent disappearance of [TPP $^{+-}$from the spectrum would indicate that charge exchange was occurring in the cell. These experiments were unsuccessful, although the failure could be due to exchange reactions occurring in the plasma adjacent to the sample surface rather than in the cell.

The presence of a strong [ $\mathrm{TPP}^{-}{ }^{-}$in the negative ion spectrum (Figure 1b) is explained by the high electron affinity $(E A)$ of TPP $(E A=1.7 \mathrm{eV})$. Again, the mechanism for molecular ion formation could be charge exchange with an anion (reaction 4), most likely from $\mathrm{KBr}$-derived ions because $\mathrm{M}^{-}$was rarely observed, or simply due to electron capture (reaction 5):

$$
\begin{aligned}
& \mathrm{TPP}+\mathrm{A}^{-} \rightarrow[\mathrm{TPP}]^{-}+\mathrm{A} \\
& \mathrm{TPP}+\mathrm{e}^{-} \rightarrow[\mathrm{TPP}]^{-}
\end{aligned}
$$

Ejection studies confirm that neither $\mathrm{Br}^{-}(\mathrm{EA}=3 \mathrm{eV})$, which is formed in large quantities, nor adduct ions, such as $\mathrm{KBr}_{\mathbf{2}}^{-}$participate in gas-phase reactions with the free porphyrin in the cell. Instead, the likely mechanism for ion formation is electron capture. As will be demonstrated, if plasma ignition of the stainless steel surface occurs, a large population of low-energy electrons is generated that will readily attach to desorbed TPP. Confirmation that plasma ignition is a prerequisite for [TPP ${ }^{-}$formation will be demonstrated later.

One additional mechanism for porphyrin ion formation shown in Figure 1 is metallation of the porphyrin ring (reactions 6-8):

$$
\begin{aligned}
\mathrm{TPP}+\mathrm{M}^{+} \rightarrow[\mathrm{TPP}-2 \mathrm{H}+\mathrm{M}]^{+} \\
\text {or }[\mathrm{TPP}-2 \mathrm{H}+\mathrm{M}]^{+}+\mathrm{H}_{2} \\
{[\mathrm{TPP}]^{-+}+\mathrm{M} \rightarrow[\mathrm{TPP}-2 \mathrm{H}+\mathrm{M}]^{-} } \\
\text {or }[\mathrm{TPP}-2 \mathrm{H}+\mathrm{M}]^{-+}+\mathrm{H}_{2} \\
{\left[\mathrm{TPP}^{++}+\mathrm{M} \rightarrow[\mathrm{TPP}-2 \mathrm{H}+\mathrm{M}]^{+}\right.} \\
\text {or }[\mathrm{TPP}-2 \mathrm{H}+\mathrm{M}]^{+}+\mathrm{H}_{2}
\end{aligned}
$$

This process, which is the subject of considerable interest in porphyrin solution chemistry, involves expulsion of $\mathrm{H}_{2}$ and replacement by a metal $[1,4]$. Metallation of the porphyrin ring can also be observed in the gas phasc, although a systematic study has not been conducted. Recent studies by Irikura and Beauchamp [34] of reactions involving laser-desorbed metals and background neutral porphine under controlled conditions define at least one mechanism (reaction 6) as involving the metal cation reaction with the neutral gas-phase porphyrin. An inability to directly observe metallated porphyrin anion products was attributed to a lack of $\mathrm{M}^{-}$; however, as we will show, $\mathrm{M}^{-}$is not essential to form the metallated porphyrin anion because, as shown in reaction 7 , an alternate pathway exists under plasma ignition conditions in which desorbed $M$ reacts with TPP $^{--}$formed by reaction 5 . Also presented in reaction 
8 is the positive ion analog in which $M$ participates in the metallation process.

\section{Plasma Effect on Laser Desorption Ionization Pathways}

We find that the most important factor in the LDI/FTICR experiment in determining the reaction pathways that will be observed is whether a laser-induced plasma is formed at the desorption site. The two experimental parameters that contribute to formation of this plasma are laser irradiance, which must be above the plasma ignition threshold for a particular metal, and sample preparation, which ensures that the metal substrate receives a sufficient thermal spike for ignition to occur. In our work, sufficient sample covered the metal surface that the first laser firing on fresh sample did not generate a plasma; however, subsequent laser firings on exposed metal produced a plasma and simultaneously desorbed porphyrin in the selvage region of the desorption site. Thus, throughout this report, spectra are distinguished as resulting from a laser firing on fresh sample under conditions that generate no plasma and subsequent laser firings on exposed metal substrate that do generate a plasma.

At this point, an explanation can be offered for the differences between the LDI/FT-ICR spectra observed by Nguyen et al. [22] and our own and, specifically, the absence of metallation products at laser irradiances to $3.8 \times 10^{7} \mathrm{~W} / \mathrm{cm}^{2}$. One possibility is that the porphyrin studied by Nguyen et al. [22] is more susceptible to cleavage than TPP at the higher irradiances required for plasma ignition. Another explanation is that conditions for plasma were never achieved in Nguyen et al. [22] because laser irradiances were relatively low, and sample preparation was described as thick $(0.5 \mathrm{~mm})$. As mentioned previously, it is for laser firings on exposed metal surface that we observed plasma ignition and the resulting positive and negative ion porphyrin metallation products.

As evidence of the distinction in reaction pathways based on laser irradiance and sample preparation, the LDI/FT-ICR spectra in Figures 2 and 3 are presented. First, the spectra in Figure 2 are acquired at increasing laser irradiance for a [TPP $-2 \mathrm{H}+\mathrm{VO}](\mathrm{VO}=$ vanadyl) and $\mathrm{KBr}$ sample on a sandblasted stainless stecl probe tip. $\Delta$ s laser irradiance was increased from $1 \times 10^{6}$ to $3 \times 10^{8} \mathrm{~W} / \mathrm{cm}^{2}$, FT-ICR spectra, along with laser plasma current (as measured by a potential drop on the front trap platc), were simultancously incasured. Up to a threshold of approximately $10^{7} \mathrm{~W} / \mathrm{cm}^{2}$, no ion current was detected on the trap plate; howcver, small amounts of $\mathrm{K}^{+}$and $\mathrm{\Lambda l}^{+}$werc obscrved in the positive ion mode. Above $10^{7} \mathrm{~W} / \mathrm{cm}^{2}$, a small current was detected on the front trap plate, and positive ion FT-ICR spectra were obtained with good signal-to-noise ratio, as shown in Figure 2a. Cation attachment products, such as $[(\mathrm{TPP}-2 \mathrm{H}+\mathrm{VO})+\mathrm{K}]^{+}$and $[(\mathrm{TPP}-2 \mathrm{H}+\mathrm{VO})+\mathrm{Al}]^{+}$, are favored, although some $\mathbf{a}$

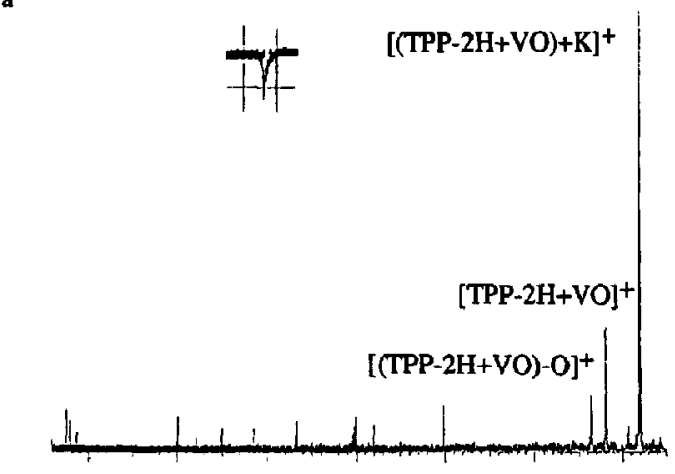

b

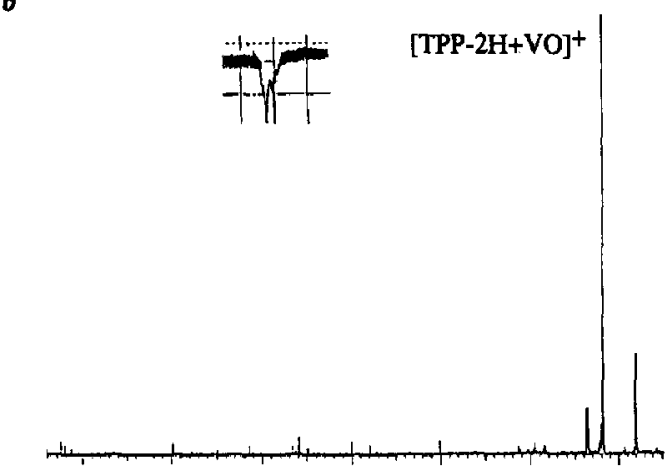

c
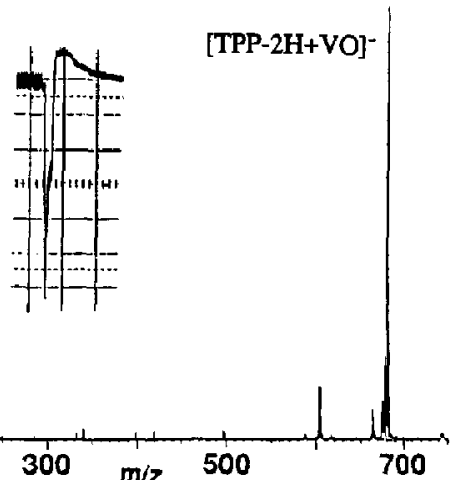

Figure 2. LDI/FI-ICR spectra of [TPP $-2 \mathrm{H}+\mathrm{VO}]$ with sample preparation and conditions as in Figure 1. (a) First laser shot at $7 \times 10^{7} \mathrm{~W} / \mathrm{cm}^{2}$ on fresh sample in the positive ion mode; (b) first laser shot at $3 \times 10^{8} \mathrm{~W} / \mathrm{cm}^{2}$ on fresh sample in the positive ion mode; (c) second laser shot at $3 \times 10^{8} \mathrm{~W} / \mathrm{cm}^{2}$ on fresh sample in the negative ion mode. The inset accompanying each spectrum is the potential drop at the front trap plate as laser-desorbed ions enter the cell.

$[\mathrm{TPP}-2 \mathrm{H}+\mathrm{VO}]^{+}$is observed at $m / z$ 679. As laser power increases, a strong plasma is formed, as indicated by a larger negative depression in the potential profile in Figure $2 b$. This negative deflection is indicative of either an excess of electrons in the plasma reaching the trap plate or a slightly better detector 


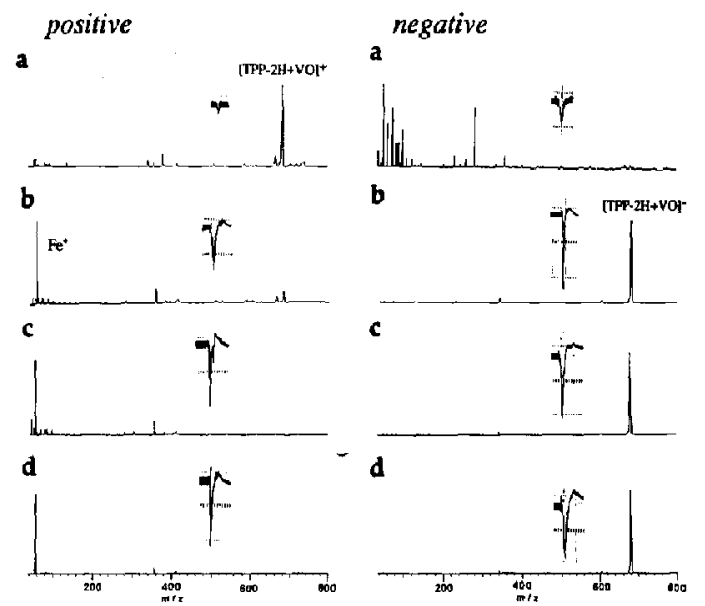

Figure 3. Companion positive and negative ion LDI/FT-ICR spectra of [TPP $-2 \mathrm{H}+$ VO] deposited with $\mathrm{KBr}$ on a sandblasted stainless steel probe tip. Spectra in (a)-(d) are from successive firings at $3 \times 10^{8} \mathrm{~W} / \mathrm{cm}^{2}$ in the same sample probe position. Each inset is the potential drop at the front trap plate as laser-desorbed ions enter the cell.

response for electrons; otherwise the quasi-neutral plasma would not exhibit a net change in charge incident on the plates, and a flat response profile would result. Associated with the much larger plasma was a marked decrease in the FT-ICR cation attachment products relative to formation of intense [TPP $2 \mathrm{H}+\mathrm{VO}^{+}$in Figure $2 \mathrm{~b}$ and $\left[\mathrm{TPP}-2 \mathrm{H}+\mathrm{VO}^{-}\right.$ shown in Figure 2c. These data indicate that in fact there is a strong correlation between the onset of plasma ignition and the commencement of reaction conditions under which charge exchange, electron detachment, or electron capture are promoted.

Additional evidence of the role that plasma ignition plays in the formation of molecular ion species was obtained from depth-profiling studies of TPP deposited on a metal substrate. The LDI/FT-ICR spectra obtained from successive firings in the same probe position with the laser operating at high laser irradiance are shown in Figure 3. A series of four successive shots are presented with spectra acquired in the positive and negative ion modes. Potential depression profiles accompany each spectrum and are a measure of the extent of plasma ignition. In evaluating the data it is important to recognize that although the FT-ICR trapped ion cell selectively captures ions of a single polarity for detection, both positive and negative ions are formed as a result of each laser desorption event. Thus, the total ion population that exists as the result of each laser firing is best represented, as shown in Figure 3, as a combination of the two spectra.

Several distinctions between positive and negative ion mode FT-ICR spectra are noted from the depthprofiling experiment. In positive ion mode, [TPP $-2 \mathrm{H}$ $+\mathrm{VO}]^{+}$is generated from an initial firing that pro- duces little plasma, but negative ions are not observed. The FT-ICR spectra for all subsequent laser firings in which a significant laser plasma is generated at the sample surface exhibit very different features. In these spectra, an intense [TPP $-2 \mathrm{H}+\mathrm{VO}^{-}$signal dominates negative ion spectra for numerous laser firings. The companion positive ion spectra for these laser firings exhibit significant metal cation $\mathrm{M}^{+}$and [TPP $2 \mathrm{H}+\mathrm{VO}^{+}$products in a ratio that is strongly dependent on laser irradiance. Little cation attachment is observed in these spectra. These results caution against assuming that a probe should be rotated to a fresh sample position without first evaluating both positive and negative ion spectra.

An explanation for the different product ions observed in the spectra shown in Figures 2 and 3 can be given simply in terms of the desorbed charged and neutral particle populations that are generated in the presence and absence of plasma ignition conditions. If there is no laser plasma, either because of reduced laser irradiance or because the sample buffers the metal surface from the photon flux, then the primary reactive ions and neutral particles generated are as depicted in Figure $4 a$ and include $M$, neutral porphyrin and porphyrin cation from the sample and $\mathrm{C}^{+}$ and $\mathrm{A}^{-}$from adventitious salts. In contrast, when plasma ignition conditions are achieved on subsequent laser firings, the particle pool shown in Figure $4 \mathrm{~b}$ is augmented by $\mathrm{e}^{-}$and $\mathrm{M}^{+}$populations. Product ions observed from reactions within this second ion pool differ in that the salts have been cleaned from the surface by the first laser firing, and, more important, an enormous thermal electron and singly charged metal ion population is generated as a result of plasma ignition.

A quick reexamination of the spectra in Figures 2 and 3 indicates consistency with the reactants depicted in Figure 4. For example, the positive ion spectra in Figures $2 a$ and $b$ and $3 a$ are derived from the particle pool in Figure 4a. Cation attachment products (reaction 1) from salts are observed. Metal cations are not observed in the absence of a plasma, which implies that the $[\mathrm{TPP}-2 \mathrm{H}+\mathrm{VO}]^{+}$peak in Figure $2 \mathrm{~b}$ must result from electron detachment (reaction 2) rather than charge exchange.

\section{Metallation Reaction with Tetraphenylporphyrin}

The competitive reactions suggested by Figure 4 also apply to metallation reactions involving TPP and the metal species arising from the substrate by laser desorption processes. Shown in Figure 5a are LDI spectra of TPP on stainless steel, which in the absence of a plasma, generate the reactant pool in Figure 4a. The sole reaction products result from cation attachment (reaction 1) to form $[\mathrm{TPP}+\mathrm{K}]^{+}$and $[\mathrm{TPP}+\mathrm{Na}]^{+}$and electron detachment (reaction 3 ) to form [TPP $]^{+}$. Products observed in the depth-profiling spectra in Figure $5 \mathrm{~b}-\mathrm{d}$ arise from the reactant pool depicted in Figure 

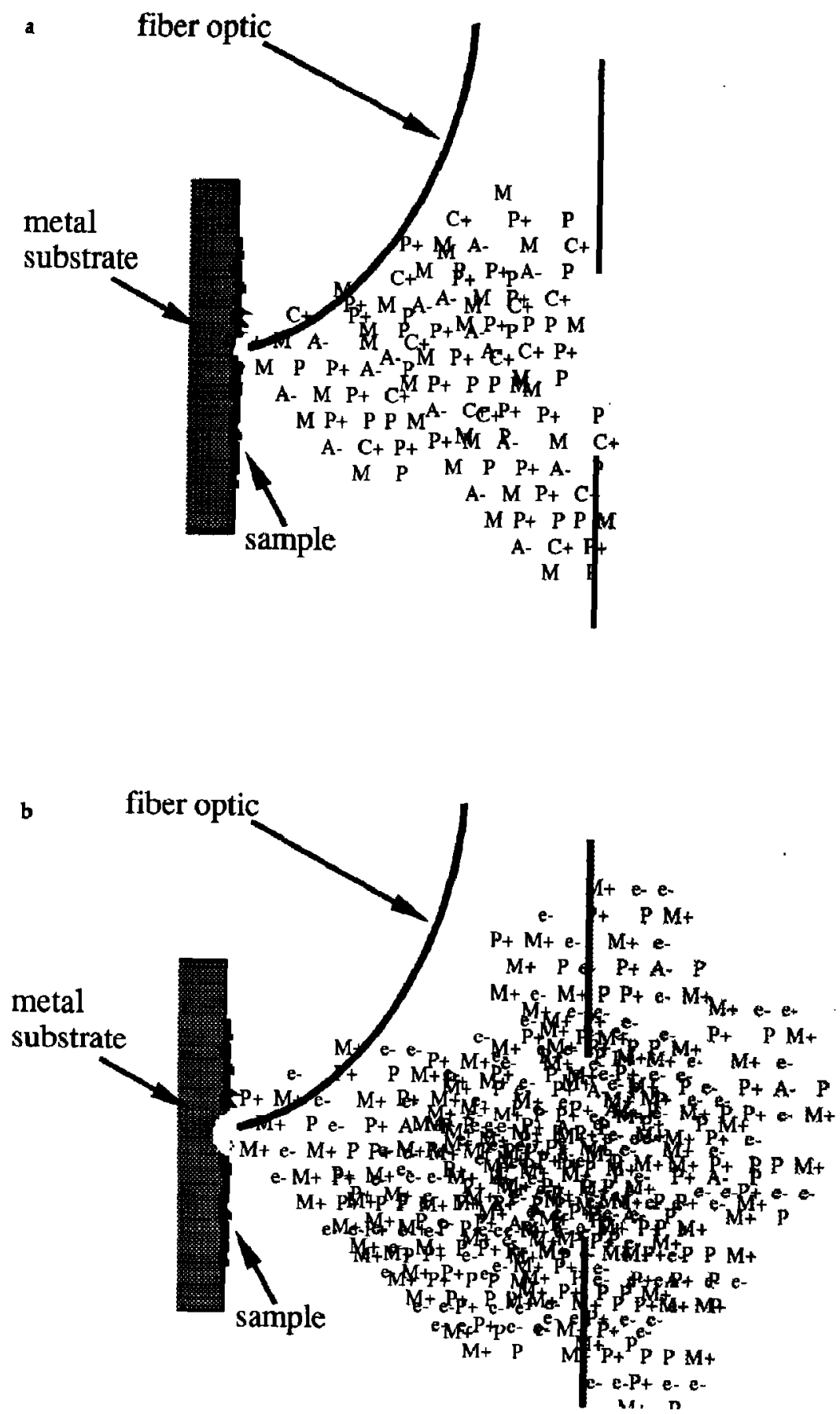

Figure 4. Depiction of predicted particle pools generated from laser desorption of TPP on metal substrates. (a) Particle desorption products in the absence of laser plasma ignition include porphyrin $(\mathrm{P})$, porphyrin cation $\left(\mathrm{P}^{+}\right)$, neutral metal $(\mathrm{M})$, and salt cations $\left(\mathrm{C}^{+}\right)$ and anions $\left(\mathrm{A}^{-}\right)$. (b) Particle desorption products following laser plasma ignition include porphyrin $(\mathrm{P})$, porphyrin cation $\left(\mathrm{P}^{+}\right)$, neutral metal (M), metal cation $\left(\mathrm{M}^{+}\right)$, and thermal electrons $\left(e^{-}\right)$. 


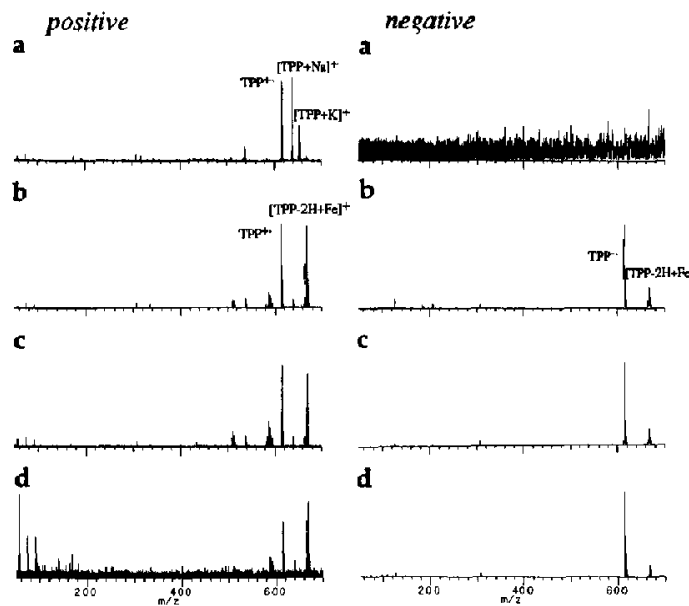

Figure 5. Companion positive and negative ion LDI/FT-ICR spectra of TPP on a sandblasted stainless steel probe tip. Spectra in (a)-(d) are from successive firings at $3 \times 10^{8} \mathrm{~W} / \mathrm{cm}^{2}$ in the same sample probe position. Spectra in (a) result from LDI on fresh sample, with product ions formed in the absence of plasma ignition conditions. Spectra in (b)-(d) exhibit product ions formed under plasmla ignition condilions.

4b. The presence of thermal electrons from plasma ignition alters the product ion distribution by opening negative ion reaction pathways. The $[\mathrm{TPP}]^{-}$. formed from electron capture (reaction 5) is the precursor ion for negative ion reactions, including porphyrin metallation (reaction 8). Also present as a result of plasma ignition is a metal cation $\mathrm{M}^{+}$population that participates in charge exchange, metallation, and transmetallation reactions that compete with electron capture for the desorbed TPP. The extent of competition depends on the availability of $\mathrm{M}^{+}$because under plasma ignition conditions, the ion can achieve kinetic energies of hundreds of electron volts that effectively remove it from the reactant pool detected by FT-ICR; however, provided that sufficient low-energy cations (less than the trapping potential) are generated, the competition with electrons will depend on the inherent reactivity of the gas-phase metal species with the porphyrin.

As the differences between positive and negative ion spectra in Figure 1 suggest, the observation of gas-phase porphyrin metallation rcactions is strongly dependent on the metal. For example, although $\mathrm{Cr}$ and Fe from stainless steel are observed to undergo metallation reactions to produce positive and negative ion species, Al metallation is only observed in the positive ion spectrum. One explanation is that, as in solution, observation of metallation products is dependent on the stability of a particular metal oxidation state. In general, if the II or III oxidation state of a metal is stable in the porphyrin, then a positive ion metallation product, either [TPP $-2 \mathrm{H}+\mathrm{M}(\mathrm{III})]^{+}$or $[\mathrm{TPP}-2 \mathrm{H}+$ $\mathrm{M}(\mathrm{II})]^{+}$, respectively, can be detected by FT-ICR. If the II or I state is possible, then a negative ion metallation product, either [TPP - $2 \mathrm{H}+\mathrm{M}(\mathrm{IT})]^{-\cdot}$ or [TPP $-2 \mathrm{H}+$ $\mathrm{M}(\mathrm{I})]^{-}$, respectively, can be detected. Thus, for example, because Al forms a stable III state, it is only observed in positive ion spectra. In contrast, $\mathrm{Fe}$ and $\mathrm{Cr}$, which form stable I, II, and III states, will generate both positive and negative ion metallation spectra.

\section{Conclusions}

The ionization of TPP and [TPP $-2 \mathrm{H}+\mathrm{VO}$ ] in a laser-desorbed metal ion plasma was detected by FTICR with abundant molecular ion species generated by competitive processes, including electron detachment, cation attachment, charge exchange, metallation, and transmetallation in the positive ion mode and electron capture, metallation, and transmetallation in the negative ion mode. The generation of $\mathrm{e}^{-}$and $\mathrm{M}^{+}$from the metal substrate by laser plasma ignition is a controlling factor in the spectra that are generated. In general, cation attachment reactions dominate positive ion spectra below the laser irradiance threshold for plasma ignition, although the metallation product from [TPP $]^{+}$ reaction with the metal atom $M$ can be observed. Under plasma ignition conditions, positive ion spectra include [TPP] ${ }^{+}$formed by charge exchange with $\mathrm{M}^{+}$ and a strong metallation product. Negative ion products are absent from the FT-ICR spectrum when a plasma is not formed; however, under plasma conditions, the intense negative ion spectra that are observed feature [TPP] ${ }^{-}$, which is formed by attachment to thermal electrons. Metallation products are also observed, evidently from reaction of $[\mathrm{TPP}]^{-'}$ with neutral M. Support for the role that plasma ignition plays was obtained from depth-profiling studies of TPP deposited on a metal substrate in which the initial firing on fresh sample did not ignite the metal substrate, but subsequent laser firings on exposed metal did yield a dense plasma of $\mathrm{e}^{-}$and $\mathrm{M}^{+}$that participated in reactions with TPP.

Metallation reactions between TPP and the laser-desorbed metal substrate were examined. Positive ion metallation products are observed both in the absence of a plasma through reaction of [TPP] ${ }^{+\cdot}$ with $\mathrm{M}$, and by a second pathway under plasma ignition conditions through reaction of TPP with $\mathrm{M}^{+}$. In negative ion mode, metallation is only obscrved under plasma ignition conditions through reaction of $[\mathrm{TPP}]^{-\cdot}$ with $\mathrm{M}$. The TPP reactivity with the metals is consistent with formation of stable metal oxidation states in the metal lated porphyrin. Specifically, the metalloporphyrin must exist as either [TPP $-2 \mathrm{H}+\mathrm{M}(\mathrm{II})]^{+}$or $[\mathrm{TPP}-$ $2 \mathrm{H}+\mathrm{M}(\mathrm{III})]^{+}$to be observed in positive ion spectra and as $[\text { TPP }-2 \mathrm{H}+\mathrm{M}(\mathrm{I})]^{-}$or $[\mathrm{TPP}-2 \mathrm{H}+\mathrm{M}(\mathrm{II})]^{-}$ to be observed in negative ion spectra. This explains the appearance of stainless steel metallation products in both positive and negative ion spectra but the appearance of aluminum metallated porphyrin only in the positive ion mode. 
From an analytical perspective, the results obtained suggest that appropriate control of the experiment, especially sample preparation and laser conditions, is critical to provide the necessary reagents to generate the porphyrin product of interest for structure determination or subsequent reactions. Of more general interest is the observation that reactions occurring in the high-energy laser-generated plasma are consistent with the results observed for porphyrin chemistry that occur in solution. This finding is important because it suggests that plasma ignition LDI might be used for generating important bioporphyrin species for subsequent gas-phase reaction in the trapped ion cell with detection by FT-ICR.

\section{Acknowledgments}

This work is suppurted by the Welch Foundation (F-1138), the Texas Advanced Technology and Research Program, and the National Science Foundation (CHE9013384) and (CHE9057097)

\section{References}

1. Smith, K. M., Eds. Porphyrins and Metalloporphyrins; Elsevier: Amsterdam, 1975.

2. Davis, B. A.; Hui, K. S.; Durden, D. A.; Boulton, A. A. Biomed. Environ. Mass Spectrom. 1976, 3, 71-76.

3. Campana, J. E. Org. Geochem. 1989, 14, 171-181.

4. Dolphyn, D., Ed. The Porphyrins, Vol. 3; Academic Press: New York, 1979.

5. Eglinton, G. In Mass Spectrometry in the Health and Life Sciences; Burlingame, A. D.; Castagnoli, N., Eds,; Elsevier: Amsterdam, 1985.

6. Gregor, I. K; Cuilhaus, M. Mass Spectrom. Reo. 1984, 3. 39-84.

7. Jiang, X; Szente, A. W.; Tolf, B.; Kehres, L. A.; Bunnenberg, E.; Djerassi, C. Tetrahedron Lett. 1984, 25, 4083-4086.

8. Tolf, B.-R; Jiang, X.-Y,; Wegmann-Szente, A.; Kehres, L. A.; Bunnenberg, E.; Djerassi, C. J. Am. Chem. Soc. 1986, 108. 1363-1374.

9. Henis, N. B.; Busch, K. L.; Bursey, M. M. Inorg. Chim. Acta 1981, 53, L31.

10. Van Berkel, G. J.; Glish, G. L.; McLuckey, S. A. J, Am. Chem. Soc. 1989, 111,6027 .

11. Van Berkel, G. J.; Glish, G. L.; Mcluckey, S. A.; Tuinman, A. A. J. Am. Chem. Soc. 1989, 111, 6027.

12. Dougherty, R. C.; Dreifuss, K. P.; Sphon, J.; Katz, J. J. I. Am. Chem. Soc. 1980, 102, 416.

13. Hunt, J. E.; McFarlane, R. D; Katz, J. J.; Dougherty, R. C. Proc. Natl. Acad. Sci. USA 1980, 77, 1745.

14. Forest, E.; Ulrich, I.; Marchon, I. C. Org. Mass Spectrom. 1987, $22,45$.

15. Gallegos, E. J; Sundararaman, P. Mass Spectrom. Rev. 1985, 4, 55.

16. Kurlansik, L.; Williams, T. J.; Strong, J. M.; Anderson, L. W.; Campana, J. E. Bioned. Mass Spectrom. 1984, 11, 475.

17. Castro, A. J.; Van Berkel, G. J.; Doolittle, F, G.; Filby, R. H. Org. Geochem. 1989, 14, 193-202.

18. Musselman, B. D.; Watson, J. T, Chang, C. K. Org. Mass Spectrom. 1986, 21, 215.
19. Naylor, S.; Hunter, C. A.; Cowam, J. A.; Lamb, J. H.; Sanders, J. K. M. 1. Am. Chern. Soc. 1990, 112, 6507-6514.

20. Forest, E.; Marchon, J.-C.; Wilkins, C. L.; Yang, L.C. Org. Mass Spectrom. 1989, 24, 197-200.

21. Brown, R. S.; Wilkins, C. L. Anal. Chem. 1986, 58, 3196-3199.

22. Nguyen, T. H.; Clezy, P. S; Willett, G. D.; Paul, G. L.; Tann, J.; Derrick, P. Org. Mass Spectrom. 1991, 26, 215-226.

23. Lias, S. G.; Bartmess, J. E.; Liebman, J. F.; Holmes, J. L.; Levin, R. D.; Mallard, W. G. J. Phys. Chem. Ref. Data 1988, 17. Suppl. 1.

24. Lias, S. G.; Bartmess, J. E.; Liebman, J. F.; Holmes, J. L.; Levin, R. D.; Mallard, W. G. J. Phys. Chem. Ref. Data 1988, 17. Suppl. 1.

25. Chen, H. L.; Pan, Y. H.; Groh, S.; Hagan, T. E.; Ridge, D. P. J. Am. Chem. Soc. 1991, 113, 2766.

26. Dillow, G. W; Gregor, 1. K, Org, Mass Spectrom. 1988, 23, 777.

27. Bowie, J. H. Mass Spectront. Rev. 1984, 3, 161-207.

28. Ferguson, E. E. Can. I. Chem. 1969, 47, 1815-1820.

29. Budzikiewicz, H. Mass Spectrom. Rev. 1986, 5, 345-380.

30. Vertes, A.; DeWolf, M.; Juhasz, P.; Gijbels, R. Anal. Chem. $1989,61,1029$.

31. Demtroder, W.; Jantz, W. Plasma Phys. 1980, 12, 691.

32. Beu, S. C.; Hendrickson, C. L.; Vartanian, V. H.; Laude, D. A. Jr. Int. J. Mass Spectrom. Lon Processes 1992, 113, 59.

33. Cody, K. B.; Burnier, K. C.; Reents, W. D. Jr.; Carlin, 1. J; McCrerey, D. A.; Lengel, R. K.; Freiser, B. S. Int. J. Mass Spectrom. Ion Phys, 1980, 33, 37.

34. Irikura, K. K.; Beauchamp, J. L. J. Am. Chem. Soc. 1991, 113, $2767-2768$.

35. Cotter, R. J.; Tabet, J.-C. Int. I. Mass Spectrom. Ion Processes 1983, 53, 151.

36. Hogan, J. H.; Beu, S. C.; Majidi, V.; Laude, D. A. Jr. Anal. Chem. 1991, 63, 1452.

37. Beu, S. C.; Laude, D. A. Anal. Chem. 1991, 63, 2200.

38. Wilkins, C. L.; Yang, C. L. C. Int. I. Mass Spectrom. Ion Processes 1986, 72, 195.

39. Wilkins, C. L.; Weil, D. A.; Yang, C. L. C.; ljames, C. F. Anal. Chem. 1985, 57, 520.

40. Brown, R. S.; Weil, D. A.; Wilkins, C. L. Macromolecules 1986, $19,1255$.

41. Johlman, C. L.; Wilkins, C. L.; Hogan, J. D.; Donovan, T. L.; Laude, D. A. Jr.; Youssefi, M.-J. Anal. Chem. 1990, 62, 1167.

42. Asamoto, B.; Young, J. R.; Citerin, R. Anal. Chem. 1990, 62, 61.

43. McCrery, D. A.; Gross, M. L. Anal. Chim. Acta 1985, 178, 91.

44. Shomo, R. E.; Marshall, A. G. Antal. Chem. 1985, 57, 2940.

45. Hogan, J. H.; Laude, D. A. Jr. Anal. Chem. 1992, 64, 763.

46. Hogan, J. H.; Laude, D. A. Jr. Anal. Chem. 1991, 63, 2105.

47. Hogan, J. H.; Laude, D. A. Jr. J. Am. Soc. Mass Spectrom. 1992, 3, 301 .

48. Van der Peyl, G. ]. Q.; Haverkamp, J.; Kistemaker, I'. G. Int. J. Mass Spectrom. Ion Processes 1982, 42, 125-141.

49. Van Breeman, R. B.; Snow, M.; Cotter, R. J. Int. I. Mass Spectrom. Ion Processes 1983, 49, 35-50.

50. Michiels, E.; Mauney, T.; Adams, F.; Gijbels, R. Int. I. Mass Spectrom. Ion Processes 1984, 61, 231-246.

51. Lindholm, E. Adv. Chem. Ser. 1966, 58, 1-19.

52. Beu, S. C.; Laude, D. A. Jr. Int. I. Mass Spectrom. Ion Processes 1990, 97, 295-310. 